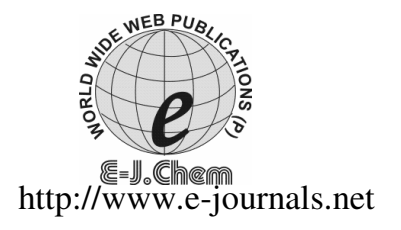

\title{
Syntheses of Some 3,5-Diaryl-4H-1,2,4-triazole Derivatives and their Antifungal Activity
}

\author{
RAM JANAM SINGH * and DHARMENDRA KUMAR SINGH \\ *Quality Control Laboratory, Indian Oil Corporation Ltd., \\ Panipat Refinery Panipat, Haryana-132140 India. \\ Department of Chemistry, Synthetic Research Laboratory, \\ Faculty of Science, Tilak Dhari Post Graduate College, Jaunpur-222002, India. \\ singhram@iocl.co.in
}

Received 3 May 2009; Accepted 1 July 2009

\begin{abstract}
Syntheses of a series of 3, 5-diaryl-4H-1, 2, 4-triazole derivatives are described. In this present work, 4-amino-3-phenyl-5- $p$-tolyl-4H-1,2,4-triazole(1) was converted to $N, N^{\prime}$-bis[3-phenyl-5-p-tolyl-4H-1,2,4-triazolyl]-1,4-xylenediimine(2) and 3-Phenyl-5-p-tolyl-4-[4-methyl benzylidenamino]-4H-1,2,4-triazole (3) in good yields by treatment with aldehydes $\mathrm{OHC}-\mathrm{C}_{6} \mathrm{H}_{4}-\mathrm{CHO}$ and $\mathrm{Ar}-\mathrm{CHO}$ respectively. The compounds $N, N^{\prime}$-bis [3-phenyl-5- $p$-tolyl-4H-1,2,4-triazolyl]-1,4-xylenediimine (2) and 3-phenyl-5-p-tolyl-4-[4-methyl benzylidenamino]-4H-1,2,4-triazole (3) were reduced with $\mathrm{NaBH}_{4}$ to afford the corresponding compounds $N, N$ '-bis [3-phenyl-5-ptolyl-4H-1,2,4-triazolyl]-1,4-xylenediamine (4) and 3-phenyl-5-p-tolyl-4-[4-methyl benzylamino]-4H-1,2,4-triazole (5) respectively. The newly synthesized compounds were characterized by spectral and elemental analyses. All the synthesized compounds were tested for their antifungal activity against P.oryzae, B. cinerea, A. niger, $C$. albicans and T. rubrum.
\end{abstract}

Keywords: 1, 2, 4-Triazole, Benzoylhydrazone, Hydrazine hydrate, Antifungal activity.

\section{Introduction}

The chemistry of heterocyclic compounds continuously to be an explore field in the organic chemistry. The importance of triazole derivative lies in the field that these have occupied a unique position in heterocyclic chemistry due to their antimicrobial activity ${ }^{1-3}$.

1, 2, 4-Triazoles and their derivatives represent one of the most biologically active classes of compounds, possessing a wide range of therapeutic properties ${ }^{4}$. In views of these observations and in continuation of our earlier work $^{5-11}$ on the syntheses of some 1,2,4- and 1,2,3- triazole derivatives, we now report the syntheses of some more triazoles derived from 4-amino-3-phenyl-5- $p$-tolyl-4H-1,2,4-triazole and their antifungal activity. 
Compounds $N, N^{\prime}$-bis [3-phenyl-5-p-tolyl-4H-1,2,4-triazolyl]-1,4-xylenediimine (2) and 3-phenyl-5-p-tolyl-4-[4-methyl benzylidenamino]-4H-1,2,4-triazole (3) were obtained by the condensation of 4-amino-3-phenyl-5-p-tolyl-4H-1,2,4-triazole (1) with aldehydes $\mathrm{OHC}-\mathrm{C}_{6} \mathrm{H}_{4}-$ $\mathrm{CHO}$ and $\mathrm{Ar}-\mathrm{CHO}$ in glacial acetic acid respectively. Compounds $N, N^{\prime}$-bis [3-phenyl-5-p-tolyl4H-1,2,4-triazolyl]-1,4-xylenediamine (4) and 3-phenyl-5-p-tolyl-4-[4-methyl benzylamino]-4H1,2,4-triazole (5) were obtained from compounds $N, N^{\prime}$-bis [3-phenyl-5-p-tolyl-4H-1,2,4triazolyl]-1,4-xylenediimine (2) and 3-phenyl-5-p-tolyl-4-[4-methyl benzylidenamino]-4H-1,2,4triazole (3) by using $\mathrm{NaBH}_{4}$ as a reducing agent.

\section{Experimental}

Melting and boiling points were determined on a Gallen Kamp apparatus in open capillaries and are uncorrected. IR spectra $\left(\mathrm{KBr}\right.$ in $\left.\mathrm{cm}^{-1}\right)$ were recorded on a Jasco FT-IR 5300 spectrophotometer and PMR spectra (DMSO-d6) on a Varian EM-390 spectrometer using TMS as an internal standard (chemical shift in $\delta \mathrm{ppm}$ ). Mass spectra were recorded on a Jeol JMS-D 300 Mass spectrometer operating at $70 \mathrm{eV}$. The purity of the compounds was confirmed by TLC using silica gel G and purified by column chromatography. For TLC, Merck silica gel $60 \mathrm{G}$ plate was used. For column chromatography, Merck silica gel 60 $(0.063-0.200 \mathrm{~mm})$ was used. The necessary chemicals were obtained from Merck and Fluka. All compounds showed satisfactory elemental analyses.

\section{4-Amino-3-phenyl-5-p-tolyl-4H-1,2,4-triazole (1)}

Ethyl $p$-methylbenzoate benzoylhydrazone $(0.01 \mathrm{~mol})$ was reacted with hydrazine hydrate $(0.01 \mathrm{~mol})$ in $40 \mathrm{~mL}$ of 1-propanol and the mixture was refluxed for $30 \mathrm{~h}$. On cooling the mixture, separated crude product was filtered, dried, washed with $30 \mathrm{~mL}$ of benzene. The insoluble part in benzene was recrystallized from 1-propanol to yield the compound (1), (yield 85\%), m.p. $284{ }^{\circ} \mathrm{C}$, Anal.Calc. for $\mathrm{C}_{15} \mathrm{H}_{14} \mathrm{~N}_{4}$ : C, 71.92; H, 5.54; N, 22.29\%; Found: C, 72.02; H, 5.20; N, 22.56\%. IR (KBr): 3344,3248 $\left(\mathrm{NH}_{2}\right), 1620(\mathrm{C}=\mathrm{N})$ and 825,767,695 $\mathrm{cm}^{-1}$ (aromatic ring); PMR: $\delta 2.37\left(1 \mathrm{H}, \mathrm{s}, \mathrm{CH}_{3}\right) ; 6.28\left(2 \mathrm{H}, \mathrm{s}, \mathrm{NH}_{2}\right), 7.31(2 \mathrm{H}, \mathrm{d}, \mathrm{Ar}-\mathrm{H}), 7.49(3 \mathrm{H}, \mathrm{m}$, $\operatorname{Ar}-\mathrm{H}), 7.97(2 \mathrm{H}, \mathrm{d}, \mathrm{Ar}-\mathrm{H})$ and $8.11 \mathrm{ppm}(2 \mathrm{H}, \mathrm{m}, \mathrm{Ar}-\mathrm{H})$; MS : $\mathrm{m} / z 209\left(\mathbf{M}^{+}\right)$other peaks were observed at $157,141,126,104,85,73$ and 45 .

\section{N,N'-Bis[3-phenyl-5-p-tolyl-4H-1,2,4-triazolyl]-1,4-xylenediimine (2)}

Compound (1) $(0.01 \mathrm{~mol})$ was reacted with corresponding aldehyde $\left(\mathrm{OHC}-\mathrm{C}_{6} \mathrm{H}_{4}-\mathrm{CHO}\right)$ $(0.01 \mathrm{~mol})$ in $30 \mathrm{~mL}$ of glacial acetic acid and the mixture was refluxed for $5 \mathrm{~h}$. On cooling the mixture, poured into a beaker containing $80 \mathrm{~mL}$ of ice water. The precipitate formed was filtered, dried and the product was recrystallized from acetic acid to yield the compound (2), (yield 85\%), m.p. $305{ }^{\circ} \mathrm{C}$, Anal.Calc. for $\mathrm{C}_{38} \mathrm{H}_{30} \mathrm{~N}_{8}: \mathrm{C}, 78.15 ; \mathrm{H}, 5.78 ; \mathrm{N}, 15.89 \%$; Found: C, 77.98; H, 5.91; N, 15.91\%. IR (KBr): $1598(\mathrm{C}=\mathrm{N})$ and $698 \mathrm{~cm}^{-1}$ (aromatic ring); PMR: $\delta 2.52$ $\left(6 \mathrm{H}, \mathrm{s}, 2 \mathrm{CH}_{3}\right) ; 7.32(4 \mathrm{H}, \mathrm{d}, \mathrm{Ar}-\mathrm{H}), 7.50(6 \mathrm{H}, \mathrm{s}, \mathrm{Ar}-\mathrm{H}), 7.72(4 \mathrm{H}, \mathrm{d}, \mathrm{Ar}-\mathrm{H}), 7.81(4 \mathrm{H}, \mathrm{m}, \mathrm{Ar}-\mathrm{H})$, $7.92(4 \mathrm{H}, \mathrm{s}, \mathrm{Ar}-\mathrm{H})$ and $8.70 \mathrm{ppm}(2 \mathrm{H}, \mathrm{s}, \mathrm{C}-\mathrm{H})$; $\mathrm{MS}: \mathrm{m} / \mathrm{z} 237\left(\mathrm{M}^{+}\right)$other peaks were observed at $189,169,131,116,83$ and 48 .

\section{3-Phenyl-5-p-tolyl-4-[4-methyl benzylidenamino]-4H-1,2,4-triazole (3)}

Compound (1) (0.01 mol) was reacted with corresponding aldehyde (Ar-CHO) (0.01 mol) in the presence of $30 \mathrm{~mL}$ of glacial acetic acid; was refluxed for $5 \mathrm{~h}$. On cooling the mixture, poured into a beaker containing $80 \mathrm{~mL}$ of ice water. The precipitate formed was filtered, dried and the product was recrystallized from ethanol-water (1:1) to yield the compound (3), (yield 90\%), m.p. $180{ }^{\circ} \mathrm{C}$, Anal.Calc. for $\mathrm{C}_{23} \mathrm{H}_{20} \mathrm{~N}_{4}$ : C, 78.28; H, 5.75; N, 15.92\%; Found: C, 
78.21; H, 5.93; N, 15.93\%. IR (KBr): $1600(\mathrm{C}=\mathrm{N})$ and $695 \mathrm{~cm}^{-1}$ (aromatic ring); PMR: $\delta$ $2.35\left(3 \mathrm{H}, \mathrm{s}, \mathrm{CH}_{3}\right), 2.45\left(3 \mathrm{H}, \mathrm{s}, \mathrm{CH}_{3}\right), 7.32(4 \mathrm{H}, \mathrm{d}, \mathrm{Ar}-\mathrm{H}), 7.40(4 \mathrm{H}, \mathrm{m}, \mathrm{Ar}-\mathrm{H}), 7.70(3 \mathrm{H}, \mathrm{m}, \mathrm{Ar}-$ $\mathrm{H}), 7.81(2 \mathrm{H}, \mathrm{m}, \mathrm{Ar}-\mathrm{H}), 7.95(2 \mathrm{H}, \mathrm{m}, \mathrm{Ar}-\mathrm{H})$ and $8.60 \mathrm{ppm}(1 \mathrm{H}, \mathrm{s}, \mathrm{C}-\mathrm{H}) ; \mathrm{MS}: \mathrm{m} / \mathrm{z} 239(\mathrm{M}+)$ other peaks were observed at 188,139,126,118, 96,79 and 41 .

\section{N,N'-Bis[3-phenyl-5-p-tolyl-4H-1,2,4-triazolyl]-1,4-xylenediamine (4)}

The corresponding compounds (2) $(0.01 \mathrm{~mol})$ was dissolved in $60 \mathrm{~mL}$ of dried methanol and $\mathrm{NaBH}_{4}(0.01 \mathrm{~mol})$ was added in small portion of the solution. The mixture was refluxed for $30 \mathrm{~min}$ and then allowed to cool. After evaporation at $35{ }^{\circ} \mathrm{C}$ under reduced pressure, the solid residue was washed with cold water. After drying, the solid product was recrystallized from ethanol to yield the compound (4), (yield 85\%), m.p. $325{ }^{0} \mathrm{C}$, Anal.Calc. for $\mathrm{C}_{38} \mathrm{H}_{34} \mathrm{~N}_{8}$ : C, 78.38; H, 5.88; N, 15.88\%; Found: C, 77.58; $\mathrm{H}, 5.90 ; \mathrm{N}, 15.89 \%$. IR $(\mathrm{KBr}): 3306(\mathrm{~N}-\mathrm{H}), 1618(\mathrm{C}=\mathrm{N})$ and $819,768,731,692 \mathrm{~cm}^{-1}$ (aromatic ring); PMR: $\delta 2.52\left(6 \mathrm{H}, \mathrm{s}, 2 \mathrm{CH}_{3}\right) ; 3.65\left(4 \mathrm{H}, \mathrm{d}, 2 \mathrm{CH}_{2}\right), 7.10(2 \mathrm{H}, \mathrm{t}, 2 \mathrm{NH}), 6.55$ $(4 \mathrm{H}, \mathrm{s}, \mathrm{Ar}-\mathrm{H}), 7.39(4 \mathrm{H}, \mathrm{m}, \mathrm{Ar}-\mathrm{H}), 7.55(6 \mathrm{H}, \mathrm{s}, \mathrm{Ar}-\mathrm{H})$ and $7.88 \mathrm{ppm}(8 \mathrm{H}, \mathrm{m}, \mathrm{Ar}-\mathrm{H})$; MS : $\mathrm{m} / \mathrm{z} 236\left(\mathrm{M}^{+}\right)$other peaks were observed at 199,159,129,126,96,76 and 47.

\section{3-Phenyl-5-p-tolyl-4-[4-methyl benzylamino]-4H-1,2,4-triazole (5)}

The corresponding compounds (3) $(0.01 \mathrm{~mol})$ was dissolved in $60 \mathrm{~mL}$ of dried methanol and $\mathrm{NaBH}_{4}(0.01 \mathrm{~mol})$ was added in small portion of the solution. The mixture was refluxed for 30 minutes and then allowed to cool. After evaporation at $35{ }^{\circ} \mathrm{C}$ under reduced pressure, the solid residue was washed with cold water. After drying, the solid product was recrystallized from ethyl acetate to yield the compound (5), (yield 92\%) m.p. $182{ }^{\circ} \mathrm{C}$, Anal.Calc. for $\mathrm{C}_{23} \mathrm{H}_{22} \mathrm{~N}_{4}$ : C, 77.84; H, 6.25; N, 15.87\%; Found: C, 78.16; $\mathrm{H}, 6.18 ; \mathrm{N}, 15.82 \%$. IR $(\mathrm{KBr}): 3302(\mathrm{~N}-\mathrm{H}), 1616(\mathrm{C}=\mathrm{N})$ and $825,770,695 \mathrm{~cm}^{-1}$ (aromatic ring); PMR: $\delta 2.31\left(3 \mathrm{H}, \mathrm{s}, \mathrm{CH}_{3}\right) ; 2.46\left(3 \mathrm{H}, \mathrm{s}, \mathrm{CH}_{3}\right), 3.72\left(2 \mathrm{H}, \mathrm{d}, \mathrm{CH}_{2}\right), 5.31(1 \mathrm{H}, \mathrm{t}, \mathrm{NH})$, $6.71(2 \mathrm{H}, \mathrm{d}, \mathrm{Ar}-\mathrm{H}), 6.95(2 \mathrm{H}, \mathrm{d}, \mathrm{Ar}-\mathrm{H}), 7.33(2 \mathrm{H}, \mathrm{d}, \mathrm{Ar}-\mathrm{H}), 7.51(2 \mathrm{H}, \mathrm{m}, \mathrm{Ar}-\mathrm{H}), 7.85$ (4H,d, Ar-H) and $7.88 \mathrm{ppm}(1 \mathrm{H}, \mathrm{m}, \mathrm{Ar}-\mathrm{H})$; MS: $\mathrm{m} / z 235\left(\mathrm{M}^{+}\right)$other peaks were observed at $179,149,129,116,89,75$ and 51 .

\section{Antifungal activity}

Four compounds were evaluated for their fungicidal activity against P.oryzae, B. cinerea, A. niger, C. albicans and T. rubrum at $1000 \mathrm{ppm}, 500 \mathrm{ppm}$ and $100 \mathrm{ppm}$ concentrations, respectively by food poisoning of solidified agar technique ${ }^{12-14}$. The inhibitory activities were compared with commercial fungicide Griseofulvin (standard drug) under similar conditions. The mould cultures used were 7 days old. The results are presented in Table 1 . The percentage inhibition after the incubation for 24,48 and $72 \mathrm{~h}$ was calculated by following equation:

$$
\text { Percentage inhibition }=(\mathrm{C}-\mathrm{T}) \times 100 / \mathrm{C}
$$

Where, $\mathrm{C}=$ Diameter of Fungus colony $(\mathrm{mm})$ in control plates

$\mathrm{T}=$ Diameter of Fungus colony $(\mathrm{mm})$ in treated plates

It is obvious form the fungicidal screening results that the most of compounds have significant fungi toxicity at $1000 \mathrm{ppm}$ against all of five fungi, but the fungi toxicity decreases considerably upon dilution. The result indicates that all these compounds showed very good activity against P.oryzae, B. cinerea, A. niger, C. albicans and T. rubrum. (Table 1). From the above observation it is clear that the 1,2, 4-triazole derivatives are more active and play a prominent role in the antifungal activity. 
Table 1. Evaluation of antifungal activity of the compounds.

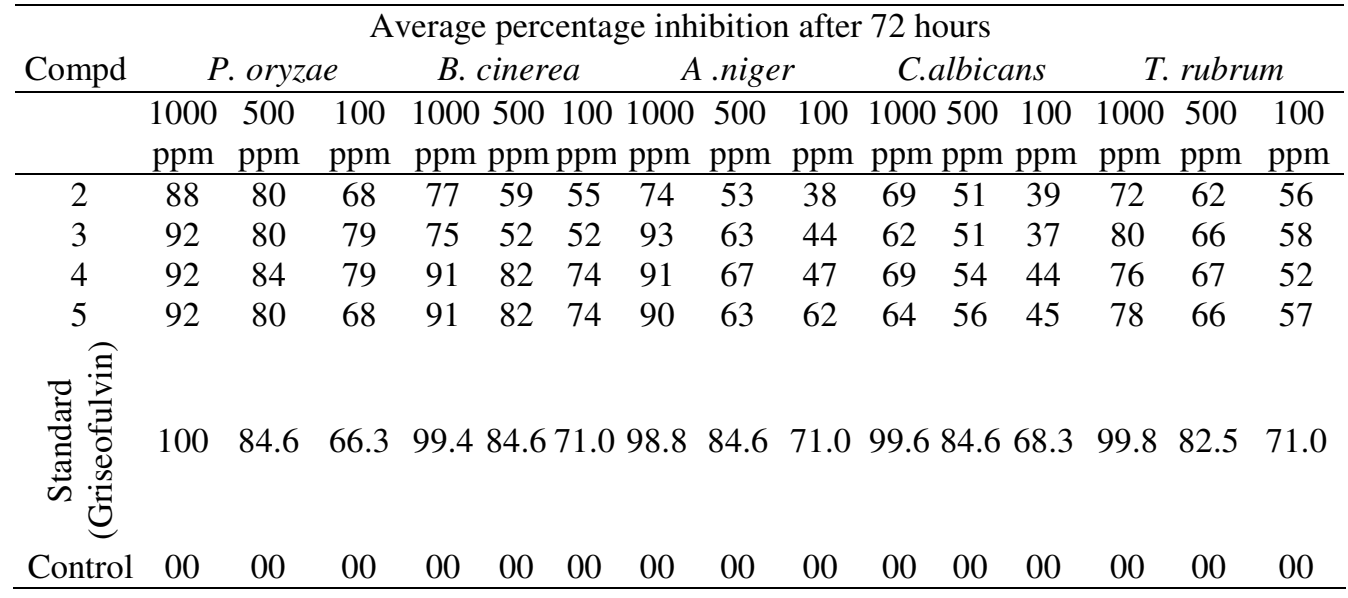

\section{Results and Discussion}

Compound 4-amino-3-phenyl-5-p-tolyl-4H-1,2,4-triazole(1) required as a starting material was obtained in one pot reaction with ethyl $p$-methylbenzoate benzoylhydrazone and hydrazine hydrate. Compounds $N, N^{\prime}$-bis [3-phenyl-5-p-tolyl-4H-1,2,4-triazolyl]-1,4xylenediimine (2) and 3-phenyl-5-p-tolyl-4-[4-methylbenzylidenamino]-4H-1,2,4-triazole (3) were obtained by the condensation of compound 4-amino-3-phenyl-5-p-tolyl-4H-1,2,4triazole(1) with aldehydes $\mathrm{OHC}-\mathrm{C}_{6} \mathrm{H}_{4}-\mathrm{CHO}$ and $\mathrm{Ar}-\mathrm{CHO}$ in glacial acetic acid. In the reduction of compounds $N, N^{\prime}$-bis [3-phenyl-5-p-tolyl-4H-1,2,4-triazolyl]-1,4xylenediimine (2) and 3-Phenyl-5-p-tolyl-4-[4-methyl benzylidenamino]-4H-1,2,4-triazole (3), the formation of compounds $N, N^{\prime}$-bis [3-phenyl-5-p-tolyl-4H-1,2,4-triazolyl]-1,4xylenediamine (4) and 3-Phenyl-5-p-tolyl-4-[4-methyl benzylamino]-4H-1,2,4-triazole (5) were possible due to possibility of the reduction of the hetero ring. However, the reduction was performed on the imino group of compounds $N, N^{\prime}$-Bis [3-phenyl-5-p-tolyl-4H-1,2,4triazolyl]-1,4-xylenediimine (2) and 3-Phenyl-5-p-tolyl-4-[4-methyl benzylidenamino]-4H1,2,4-triazole (3) without affecting the hetero ring by using $\mathrm{NaBH}_{4}$ as the selective reducing agent. (Scheme 1)

All synthesized compounds containing 1,2,4-triazole moiety is more active and plays a prominent role in antifungal activity. The structures of all the compounds are confirmed by IR, PMR, \& MS spectral data, and are further supported by correct elemental analyses. The IR spectra of compounds $N, N^{\prime}$-bis [3-phenyl-5-p-tolyl-4H-1,2,4-triazolyl]-1,4-xylenediimine (2) and 3-phenyl-5-p-tolyl-4-[4-methylbenzylidenamino]-4H-1,2,4-triazole (3) showed characteristic absorption bands between 1575 and $1600 \mathrm{~cm}^{-1}(\mathrm{C}=\mathrm{N})$. The PMR characteristic signals of compounds $N, N^{\prime}$-bis [3-phenyl-5-p-tolyl-4H-1,2,4-triazolyl]-1,4-xylenediimine (2) and 3-Phenyl-5- $p$-tolyl-4-[4-methyl benzylidenamino]-4H-1,2,4-triazole (3) were observed at $\delta$ 8.58-8.78 ppm $(1 \mathrm{H}, \mathrm{s}, \mathrm{N}=\mathrm{CH})$. The IR spectra of compounds $N, N^{\prime}$-bis [3-phenyl-5-p-tolyl- $4 \mathrm{H}$ 1,2,4-triazolyl]-1,4-xylenediamine (4) and 3-Phenyl-5-p-tolyl-4-[4-methyl benzylamino]-4H1,2,4-triazole (5) showed characteristic absorption bands between $3200-3310 \mathrm{~cm}^{-1}(\mathrm{NH})$. The PMR characteristic signals of compounds $N, N^{\prime}$-bis [3-phenyl-5- -tolyl-4H-1,2,4-triazolyl]-1,4xylenediamine (4) and 3-phenyl-5-p-tolyl-4-[4-methylbenzylamino]-4H-1,2,4-triazole (5) were a triplet at $\delta 5.30-6.30 \mathrm{ppm}(1 \mathrm{H}, \mathrm{t}, \mathrm{NH})$ and as a doublet at $\delta 3.63-4.15 \mathrm{ppm}\left(2 \mathrm{H}, \mathrm{d}, \mathrm{CH}_{2}\right)$. 


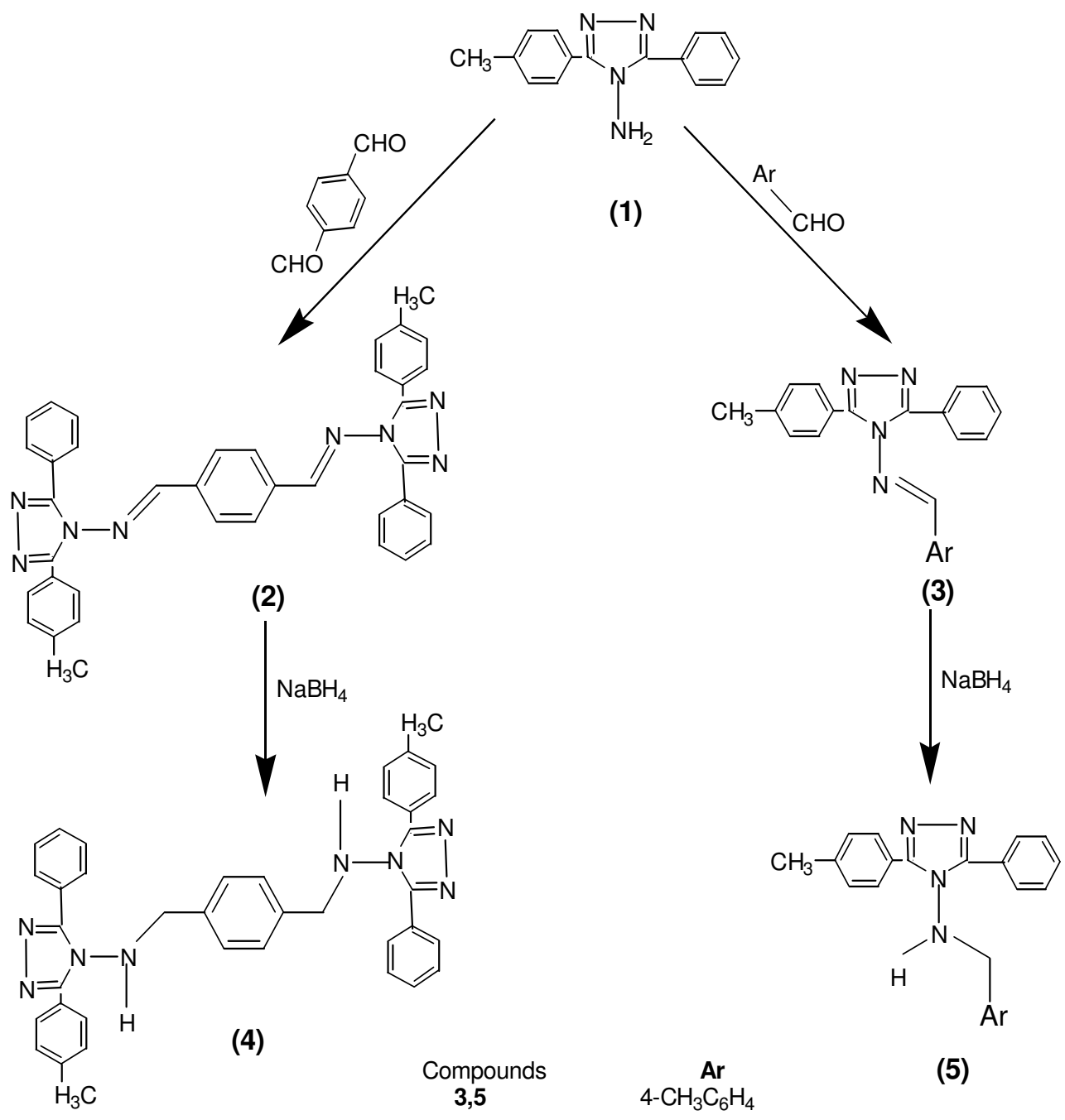

\section{Conclusion}

Scheme 1.

In conclusion, a series of 3,5-diaryl-4H-1,2,4-triazole derivatives were synthesized and characterized. The structure of all the compounds are confirmed by IR, PMR \& MS spectral data, and are further supported by correct elemental analysis. All these compounds containing $1,2,4$ - triazole moiety is more active and plays a prominent role in antifungal activity. All compounds showed significant and comparable activity with Griseofulvin against P.oryzae, B. cinerea, A. niger, C. albicans and T. rubrum at 1000 ppm concentration.

\section{Acknowledgements}

The authors are thankful to Head, RSIC, CDRI, Lucknow for analytical and spectral data, and Head of the Department of Microbiology I.M.S, B.H.U. for biological screening and to the Head of the Chemistry Department of Tilak Dhari Post Graduate College, Jaunpur for providing laboratory facilities. 


\section{References}

1 Zeeh B and Goetz H, J Indian Chem Soc., 1981, 280, 2923-2926.

2 Gamala A and Ahmed M, J Indian Chem Soc., 1997, 74, 624-625.

3 Parmar S S, Choudhary M, Choudhary S K, Kumar S and Sapiro H R, J Pharm Sci., 1977, 66, 971-973.

4. İkizler A, Demirbas N, and İkizler A A, J Heterocycl Chem., 1996, 33 ,1765-1769.

5. Singh R J, Syntheses and Antimicrobial activity of Some 1,2,4- and 1,2,3- Triazole Derivatives, Ph. D Thesis, Tilak Dhari Post Graduate College, Veer Bahadur singh Purvanchal University, Jaunpur, Uttar Pradesh, India, 2002.

6. Singh R J, Singh D K, Mahadevan K M, Indian J Heterocycl Chem., 2003, 13, 155.

7. Singh R J, Singh D K, Mahadevan K M, Vagdevi H M and Vaidha V P, Indian J Chem., 2003,42B, 1931.

8. Singh R J and Singh D K, J Purvanchal Academy of Sciences ISSN: 0972-3498, 2004.

9. $\quad$ Singh R J, J Purvanchal Academy of Sciences, 2006, 12(Sec. B), 21-24.

10. Singh R J and Singh D K, E Journal of Chemistry, 2009, 6(3), 769-800.

11. Singh R J and Singh D K, S Afr J Chem., 2009, 62,105-108.

12. Ameresh Y S and Naragund V B, Indian Phytopathological Soc., 1998, 4.

13. Tasaka A, Tamura N., Matsushita Y, Kitazaki T, Hayashi, R, Okonogi K and Iton K, Chem pharm Bull (Tokyo), 1995, 43, 432.

14. Vicentini C B, Brandolini V. Guarneri M and Giori P, II Farmaco, 1992, 1021-1034. 


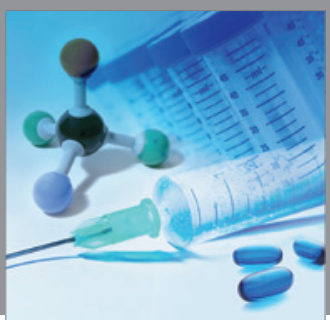

International Journal of

Medicinal Chemistry

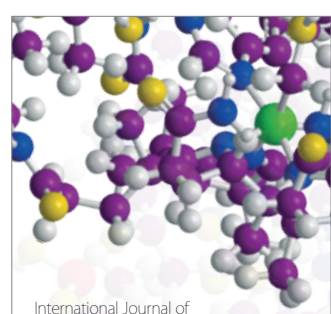

Carbohydrate Chemistry

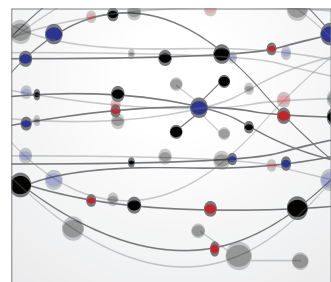

The Scientific World Journal
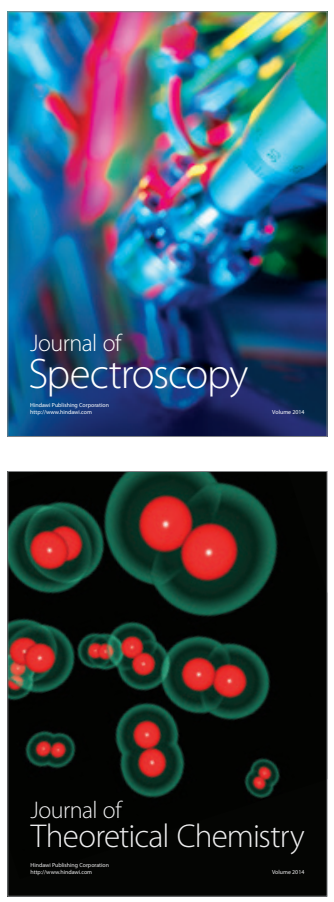
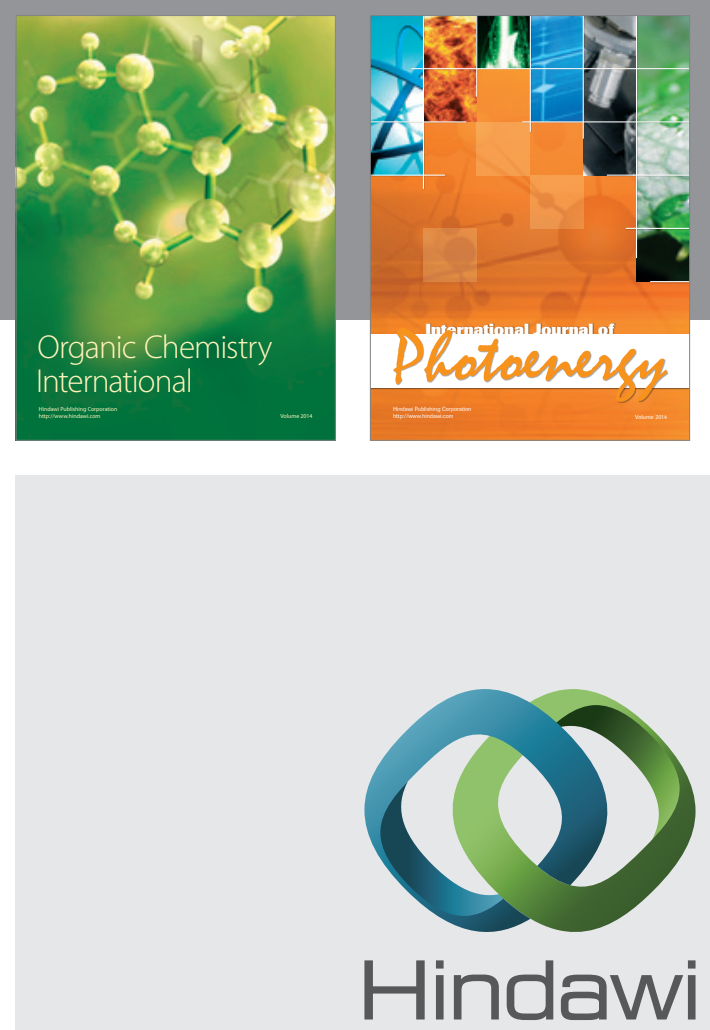

Submit your manuscripts at

http://www.hindawi.com
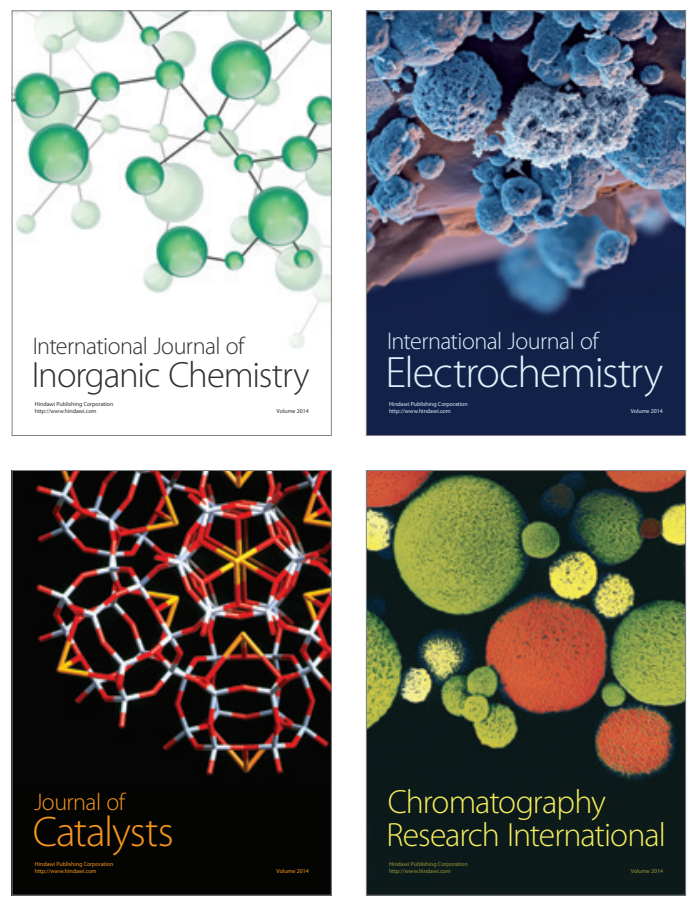
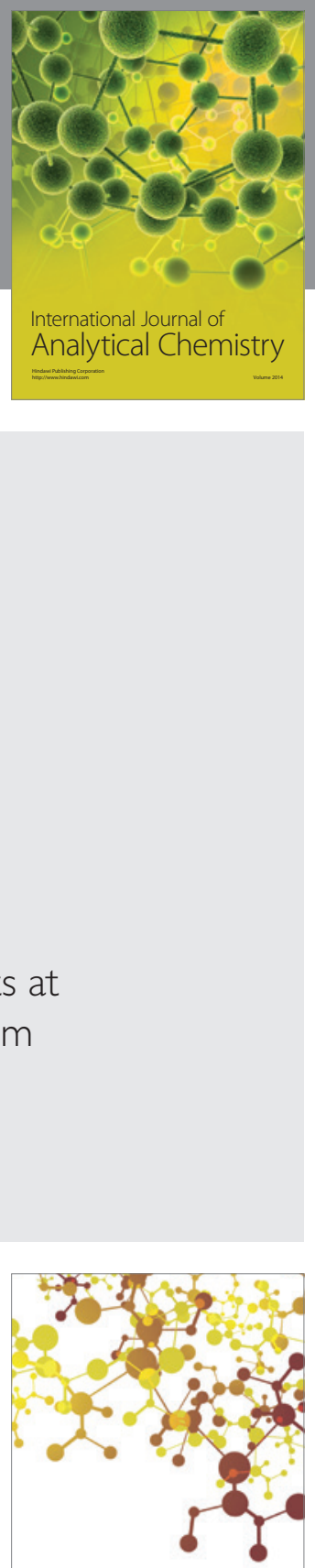

Journal of

Applied Chemistry
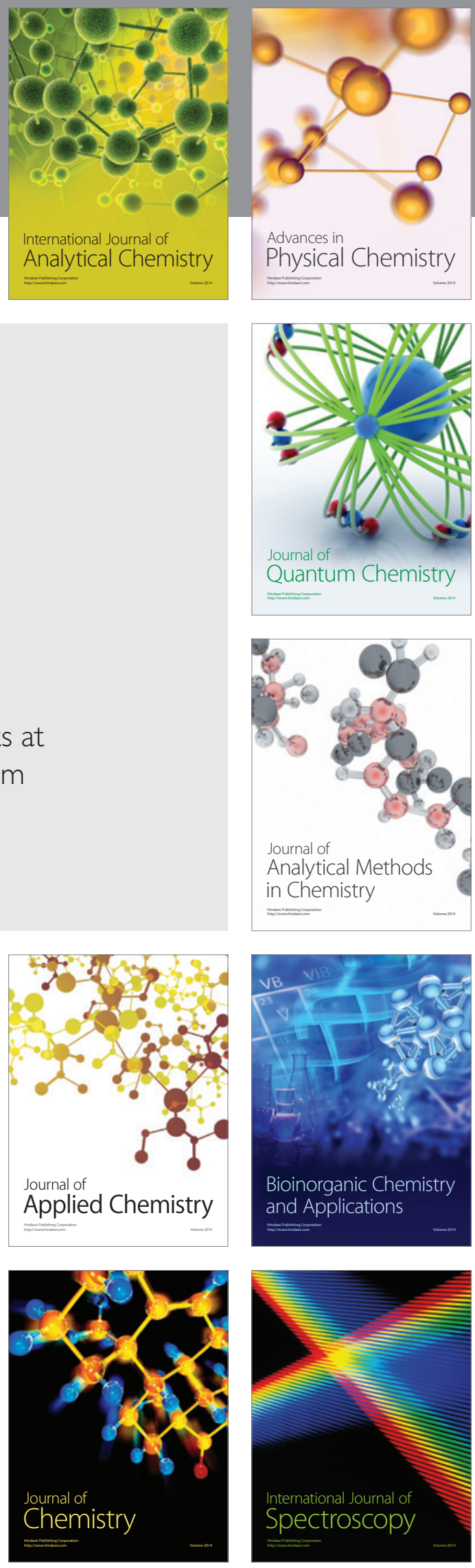